\title{
On fitting a triangle into a circle: A study on employment outcomes of adults with Fetal Alcohol Spectrum Disorder who attended postsecondary institutions
}

\author{
Cheryll Duquette and Shari Orders
}

University of Ottawa

\begin{abstract}
Aim: This study examined the employment outcomes of individuals with FASD who had undertaken postsecondary studies.

Design: A qualitative research design using inductive thematic analysis and descriptive statistics was employed.

Setting: The study took place in the United States and Canada.

Participants: Ten adoptive mothers, one birth mother, one step-mother and one mother-in-law ( $N=13$ ), representing 17 adult children, responded to the survey. Four adults with FASD who had undertaken postsecondary studies each participated in an individual interview.

Measures: An electronic survey consisting mostly of open-ended items was used to obtain data on the postsecondary and employment experiences of adults with FASD from the perspectives of their relatives. Adults with FASD participated in individual interviews in which they elaborated on their experiences.

Findings: More than half of the adults with FASD were employed, albeit mostly in the service sector and on a part-time basis. Four of the adults had received an early diagnosis, and these individuals were all employed; two were working in the area of their postsecondary studies. Six of the adults with FASD who had completed their college programs were working at the time of the research.

Conclusions: For those individuals who did not graduate or were not employed, symptoms of FASD and other disabilities (e.g., substance abuse and mental health problems) were related to these negative outcomes. However, a supportive network of friends and family contributed to success in postsecondary studies and employment.
\end{abstract}

Fetal Alcohol Spectrum Disorder (FASD) is an umbrella term that includes Fetal Alcohol Syndrome (FAS), Partial Fetal Alcohol Syndrome (pFAS), Alcohol Related Neurodevelopmental Disorder (ARND), and Alcohol Related Birth Defects (ARBD). All of these conditions are caused by prenatal exposure to alcohol and may result in dysmorphology and growth deficits (FAS) and a continuum of behavioral and cognitive difficulties caused by the primary birth defect, which is damage to the central nervous system (Chudley et al., 2005). Streissguth and O’Malley (2000) contend that unlike most birth defects, which are usually identified and surgically treated at birth, "FASD is overlooked at birth and treated later by mental health specialists—often unknowingly” (p. 1).

Obtaining a diagnosis as a child is difficult because there are often no physical signs, and no biological tests are available (Chudley, Kilgour, Cranston, \& Edwards, 2007).
Moreover, FASD may not be suspected by healthcare professionals, and consequently it is often not diagnosed until adulthood (Clark, Lutke, Minnes, \& Ouellette-Kuntz, 2004). While most individuals with FASD have an IQ score of above 70 , adults with the disability demonstrate cognitive deficits in memory, attention, processing efficiency, and learning that are beyond what would be predicted on the basis of their IQ scores alone (Kerns, Don, Mateer, \& Streissguth, 1997; Spohr, Willms, \& Steinhausen, 2007). Longitudinal studies show that these characteristics and others that are present in childhood persist in adulthood (Spohr et al., 2007; Streissguth, Barr, Kogan, \& Bookstein, 1996). Additionally, when brain damage is not suspected and the cognitive and behavioral problems that arise from it are not understood, the individual is at risk of developing secondary conditions, such as depression, suicidal ideation, and substance abuse (Streissguth et al., 2004). Streissguth and O’Malley (2000) 
reported that these other disabilities increase with age, and it is often the case that when an individual is required to undergo a diagnostic process, such as a referral to a psychologist or psychiatrist, in order to receive treatment for one of these conditions, FASD is detected as the primary disability (Clark et al., 2004).

The literature on outcome studies involving adults with FASD is thin. The few studies available point to problems with employment for this population. For example, in a 20year follow-up study on 37 German adults with FASD, Spohr and his colleagues (2007) found that although the subjects had been enrolled in preparatory job training and occupational programs as adolescents, there was a high rate of vocational problems. A similar outcome was also reported by Streissguth and O'Malley (2000) in their research involving 415 patients with FASD in the United States. Among the 90 adults (aged 21 and older), the authors reported that $80 \%$ had major problems with employment and $80 \%$ were still living dependently. Only seven of the 90 subjects lived independently and had no major employment issues. Their results also demonstrated that a diagnosis at age 26 more than doubled the estimated odds of disrupted school experience (suspension and/or dropping out), inappropriate sexual behavior, and alcohol and drug problems.

In a recent study on the adult life outcomes of 14 individuals with FASD in New Zealand, similar results were reported (Salmon \& Buetow, 2012). The researchers found that many of the individuals had a disrupted school experience due to learning and behavioral difficulties. The problems with attention and memory that these individuals experienced in childhood and adolescence persisted into adulthood and contributed to their inability to hold a job for more than a few months. They were described as gullible, unable to manage their money, lonely, unable to choose the "right" friends, and having run-ins with the law. Just two of the eight participants over 18 years were employed at the time of the interviews, and only one had held a job continuously, albeit with various employers. The participants had lived experiences of failure and marginalization, and many had a dual diagnosis of mental illness. The authors of the study identified alcohol use as both a cause and consequence of mental ill-health among all of the individuals, in that prenatal exposure to alcohol was related to their diagnoses of mental health problems and they drank to cope with them. Not surprisingly, many of the participants stated that obtaining a diagnosis had been difficult due to a lack of knowledge about FASD among medical professionals. Additionally, a few expressed frustration because they perceived themselves as not being "normal."

In sum, it is clear from the research on adults with FASD that this is a lifelong disability. However, the risk of adverse adult outcomes may be reduced by protective factors, such as living in stable, nurturing homes (especially between the ages of 8 and 12) and obtaining an early diagnosis (before the age of 6) (Spohr et al., 2007; Streissguth et al., 2004). It has also been found that having a parent who advocated for educational services and supports was linked to high school completion among individuals with FASD (Duquette, Stodel, Fullarton, \& Hagglund, 2006). Moreover, some high school graduates with FASD go on to do postsecondary work (Duquette \& Stodel, 2005). At this time, we know that life outcomes of adults with FASD frequently include a diagnosis of mental illness, unemployment, and dependent living. However, there is no research on the outcomes for adults with FASD who attended a postsecondary institution. It was therefore the purpose of this exploratory study to investigate the employment situations of adults with FASD who were, or had previously been, registered in a postsecondary program.

\section{Methods}

This exploratory study followed a qualitative approach in order to capture the participants' perspectives on their own lived experiences (Creswell, 2007). The data reported in this article are part of a larger study on the educational experiences and life outcomes of adults with FASD who were in postsecondary programs. Ethics approval was obtained to conduct this research.

\section{Recruitment}

Participants were recruited through the electronic mailing list of an Ontario FASD Support Group and FASlink. The selection criteria for the participants of the online survey were that they be a relative of an adult who (a) had a diagnosis of some type of FASD and (b) was registered in a postsecondary program at the time, or had been registered in a postsecondary program (e.g., transition, apprentice, college, or university). Only 13 women responded to the survey, which was disappointing to the researchers. It is possible that there were very few adults with FASD who had the academic qualifications, the opportunity, and the desire to attempt postsecondary studies. It may also have been the case that some students with FASD registered in postsecondary programs had not yet been diagnosed, and their families would not have received the recruitment notice for this study or would have overlooked it.

\section{Data Collection}

The researchers used an online survey and individual interviews to gather the data for this study (http://www.surveymonkey.com/s/VMHFBRP). When the survey was active, participants completed the consent form and responded to the items that elicited demographic information. Participants also had an opportunity to describe their perceptions of the postsecondary educational experiences and employment outcomes of their relatives with FASD. Questions included, for example, "Describe the postsecondary programs your child has participated in" and "What is your child with FASD doing now?" Four of these participants indicated that their adult child with FASD would be willing to participate in an individual interview. The interviews were conducted by telephone and in person; each one lasted about an hour. They provided the individuals with an opportunity to elaborate on their experiences (Marshall \& Rossman, 2006) and 
allowed the researchers to gather in-depth data. Questions included, for example, "What things help you keep a job?" and "What are your future goals?" The interviews were digitally recorded and the transcripts were typed verbatim and sent to the four adults for their review and approval.

\section{Data Analysis}

The data from the closed-ended questions in the survey were analysed descriptively, and the data from the openended items were analysed inductively. The demographic data were analysed to produce descriptive statistics on the current age and age at diagnosis of each adult with FASD and structural aspects of their families. The data from the open-ended items were coded and arranged into categories that related to postsecondary education and employment experiences. They were then cross-referenced to determine relationships between time of diagnosis and employment and between persistence in postsecondary education and employment. Tables were produced to show demographic information and life outcomes for the 17 adults with FASD (i.e., persisting in postsecondary education until graduation, and finding employment).

The interview transcripts of the four adults with FASD were read repeatedly and the data were coded and categorized (Miles \& Huberman, 1994). A table was created so that data for each of the participants could be summarized and compared across categories, and examined for emerging themes (Strauss \& Corbin, 1998). The analysis of all of the qualitative data was done by hand to increase researcher engagement with the data (Charmaz, 2000).

\section{Trustworthiness}

The two main indicators that the data collected in this study were authentic and believable were credibility and confirmability (Freeman, de Marrais, Preissle, Roulston, \& St. Pierre, 2007). Credibility refers to the correspondence between the researchers' portrayal of the participants' viewpoints and the way those individuals actually perceive the phenomena under study (Mertens, 2005). To enhance the credibility of the interview data, first-level member checks were conducted by having the four adults review and confirm the accuracy of the transcripts (Brantlinger, Jimenez, Klingner, Pugach, \& Richardson, 2005). A confirmability audit was conducted on all the qualitative data by the first author to ensure that the online data and the summaries of the interview data could be traced back to the original sources (Mertens, 2005). Finally, the two authors analysed the data independently to ensure agreement on the findings.

\section{Findings}

\section{Participants}

Ten adoptive mothers, one birth mother, one step-mother, and one mother-in-law $(N=13)$, representing 17 adult children, responded to the survey. Four of the adult children with FASD agreed to be interviewed. The survey was conducted in the United States, Canada, and elsewhere. Two of the respondents were from the United States, 10 lived in Canada, and one participant provided no indication of where she lived (see Table 1). Ten of the women commented on a single child, two of the respondents had two children (\#6a and \#6b), and one person reported on three adults in the same family (\#5a, \#5b, and \#5c). Their adult children and relatives with FASD who had attended a postsecondary program ranged in age from 19 to 44 years; the mean age was 29.8 years. A diagnosis of some form of FASD was made before the age of three for four of the children, before the age of 18 for four of them, and after age 18 for seven of the adults. Two of the participants had been told during the adoption process that their baby might have FASD. One of these stated that, at the time, she was "not too worried" about it; the other woman wrote, "I was told he had [FAS], and I did some research on it, but still, had no clue what we were in for." Other respondents expressed the emotions they felt upon receiving the diagnosis, such as grief, loss, and denial. However, others reported feeling relief at finally having a correct diagnosis. A participant wrote that she felt "relieved to have a diagnosis," and another commented, "I knew [the diagnosis] was accurate and had been trying since he was four to find out what it was." Two responses indicated that the diagnosis explained why the individual with FASD had experienced problems.

\section{High School and Postsecondary Educational Experiences}

Most of the adults attended publicly-funded high schools. Thirteen were placed in general classrooms, seven with no extra help and six with resource assistance. It is not known why some of these individuals did not receive any extra help, as resource assistance was available even in the 1980 s, when the oldest of this group was in high school. It is possible that it was not recommended by teachers, requested by the parents, or desired by the individuals. It may also have been the case that, at the time, these students did not meet the school's or district's criteria for help from the resource room teacher. Five of the adults attended residential/private schools or were homeschooled for all or part of their high school education. Eleven of the 17 adults graduated from high school, and the respondents attributed this accomplishment to strong parental involvement (academic and emotional support, advocacy) and some supportive teachers. However, six did not graduate from secondary school due to their disruptive behavior, a school setting that did not meet their needs, lack of understanding of FASD, and substance abuse. After withdrawing from high school or being expelled, respondents reported that they obtained part-time employment, enrolled in a private school, "got into trouble," or "partied a lot."

Some of the adults with FASD registered for postsecondary programs immediately after high school, while others did not. The reasons affecting the timing of entry into postsecondary education are not known. The programs for which the adults with FASD were enrolled included culinary arts, dental technology, dental assistant, medical office professional, welding, hairdressing, performing arts, 
Table 1

Demographic Information

\begin{tabular}{lllll}
\hline Adult with FASD & Male/Female & Current age & Age at diagnosis & Country \\
\hline 1 & Male & 19 & 7 & Canada \\
2 & Male & 30 & Under 3 & Canada \\
3 & Female & 22 & Not known & Canada \\
4 & Male & 41 & 38 & Canada \\
$5 \mathrm{a}$ & Not known & 38 & Not known & Canada \\
$5 \mathrm{~b}$ & Male & 38 & 17 & Canada \\
$5 \mathrm{c}$ & Male & 34 & 17 & Canada \\
$6 \mathrm{a}$ & Male & 29 & 25 & Canada \\
$6 \mathrm{~b}$ & Male & 28 & 26 & Canada \\
7 & Female & 24 & Under 3 & Canada \\
8 & Male & 26 & Under 3 & United States \\
9 & Male & 39 & 21 & Canada \\
$10 \mathrm{a}$ & Female & 26 & 25 & Canada \\
$10 \mathrm{~b}$ & Female & 21 & 11 & Canada \\
11 & Male & 21 & Under 3 & United States \\
12 & Female & 44 & 38 & Canada \\
13 & Male & 31 & 19 & Canada \\
\hline
\end{tabular}

music, and computer technology. One adult who had withdrawn from high school enrolled in online university courses after earning his GED. Another completed college, but the parent described her courses as "all over the map," suggesting that she did not have a specific program focus. Although some of the adults had contemplated dropping out, six of 17 persisted and graduated (see Table 2). Reasons for this persistence included a structured and stable academic environment; high school academic preparation; a good fit between the program and the adult's abilities and interests; and support from parents, teachers and peers. One example of support from a teacher was provided by the mother of a woman who studied hairdressing. Once the instructor was aware of the woman's learning needs, she ensured that her student with FASD had extra time to practise the skills that were being taught. However, seven of the adults withdrew from their postsecondary programs and only one of these later returned. Factors that contributed to these withdrawals included drug and alcohol use and an inability to do the work, which, in turn, led to feelings of frustration. Sometimes the decision to withdraw seemed to be made without fully reflecting on the consequences. An adoptive mother explained that one day, due to impulsivity caused by FASD, her daughter (\#10a) “decided [she] didn’t like it and walked out," not realizing that because she did not complete her program, she would have to repay the bursaries she had received.

\section{Employment}

For four of the adults with FASD, postsecondary studies led to employment in their respective fields: performing arts (dance), computer technology, hairdressing, and dental technology (see Table 2). The dental technologist (\#12) worked in her field for three years; although not certified, the computer technologist (\#6b) was employed by a large firm in his area; and the dance instructor (\#2) had kept his job for four years. However, employment experiences were not uniformly positive. One woman wrote of her daughter's experience, "She is a hairdresser, though she was fired from her first several jobs due to difficulty in following the set routines" (\#7). This participant also mentioned that her daughter did not obtain her hairdressing license because the written test "is beyond her abilities." However, with help from her mother to manage the financial aspects of the business, the young woman is selfemployed and able to work part-time.

While four of the adults did find work in their field of postsecondary study, six did not. Two of the adults were working at Walmart (\#5c, whose courses were "all over the map," and \#8, who studied welding) and another was a counsellor at a wilderness camp for troubled children (\#6a, who studied welding). The parent of siblings \#5a and \#5b indicated that they were both working (one at an FASD project), and one young man (\#11) was working part-time for an airline company while still attending school.

Of the seven adults with FASD who were not employed, five had a secondary disability (four had substance abuse problems and one had a mental illness). One of these adults was registered in a music program (\#1) and his mother wrote that he was now "on disability, doing drugs and drinking." The mother of a young woman (\#10b) provided more details about her daughter's difficulties. 
Table 2

Postsecondary Program, Persisted/Dropped Out, Current Situation

\begin{tabular}{|c|c|c|c|}
\hline $\begin{array}{l}\text { Adult } \\
\text { with } \\
\text { FASD }\end{array}$ & $\begin{array}{l}\text { Postsecondary } \\
\text { program }\end{array}$ & $\begin{array}{l}\text { Persisted/ } \\
\text { Dropped out }\end{array}$ & Current Situation* \\
\hline 1 & Music_classical guitar & Dropped out & “On disability, doing drugs and drinking, no support worker available.” \\
\hline 2 & Performing arts college & Not known & $\begin{array}{l}\text { "Attending UVIC } 6 \text { hrs. a week (auditing course) 2-year certificate program, working } \\
\text { at a coffee shop } 3 \text { hrs. a week (with support), teaching hiphop } \\
4 \text { hrs. a week and working as an FAS mentor for an FASD team in Cowichan Valley." }\end{array}$ \\
\hline 3 & Not known & Dropped out & "Still in denial; needs to go to a sober living house." \\
\hline 4 & Not known & Not known & "Nothing [except] drugs." \\
\hline $5 a$ & $\begin{array}{l}\text { MOA [Medical Office } \\
\text { Professional] course }\end{array}$ & Persisted & "Working with a project related to FASD." \\
\hline $5 b$ & $\begin{array}{l}\text { CDA [Certified Dental } \\
\text { Assistant] course in } \\
\text { college }\end{array}$ & Persisted & Working \\
\hline 5c & $\begin{array}{l}3 \text { years of college } \\
\text { completed, but courses } \\
\text { "all over the map” }\end{array}$ & Persisted & Working at Walmart \\
\hline $6 a$ & $\begin{array}{l}\text { Welding apprenticeship } \\
\text { including practicum }\end{array}$ & Not known & $\begin{array}{l}\text { "Head aboriginal counsellor at a wilderness camp for troubled kids, a high proportion } \\
\text { of whom have FASD.” }\end{array}$ \\
\hline $6 \mathrm{~b}$ & Computer tech & Not known & Main computer tech for largest local company \\
\hline 7 & $\begin{array}{l}\text { Attended hairdressing } \\
\text { school }\end{array}$ & Persisted & $\begin{array}{l}\text { "She is married, a mother of a 3-month-old baby, and a part-time self -employed } \\
\text { hairstylist." }\end{array}$ \\
\hline 9 & $\begin{array}{l}\text { Took courses towards } \\
\text { his GED }\end{array}$ & Dropped out & $\begin{array}{l}\text { "Living on his own in a small bachelor apartment. His main interest is computer } \\
\text { gaming and he is quite good at it." }\end{array}$ \\
\hline $10 \mathrm{a}$ & Not known & $\begin{array}{l}\text { Dropped out } \\
\text { and returned }\end{array}$ & $\begin{array}{l}\text { "Has been dumped by a boyfriend who was } 20 \text { years older than her but who also had } \\
\text { provided her with a stable, structured environment; she became pregnant, is not sure } \\
\text { who the father is, and is drifting from guy to guy." }\end{array}$ \\
\hline $10 \mathrm{~b}$ & Not known & Dropped out & $\begin{array}{l}\text { "Moved in with three druggy guys and has been in all kinds of trouble; is totally } \\
\text { confused why; she is very vulnerable." }\end{array}$ \\
\hline 11 & Got his GED & $\begin{array}{l}\text { Persisting, } \\
\text { still in school }\end{array}$ & "Full-time student, and is working as a baggage handler and ticket agent at airport.” \\
\hline 12 & $\begin{array}{l}\text { Dental technology, } \\
\text { Paralegal program }\end{array}$ & $\begin{array}{l}\text { Persisted in } \\
\text { both } \\
\text { programs }\end{array}$ & $\begin{array}{l}\text { "Working part-time, taking courses part-time, living independently and coping with all } \\
\text { aspects of her life [worked as dental technologist for many years]." }\end{array}$ \\
\hline 13 & Culinary arts & Dropped out & $\begin{array}{l}\text { "Nothing in the way of employment. He lives with one other young man in a } \\
\text { supported living home. The last few years have been difficult for him due to his } \\
\text { severe depression. He takes a number of medications. He spends a great deal of time } \\
\text { on his computer, does things with roommate and support workers and is always in } \\
\text { contact with family." }\end{array}$ \\
\hline
\end{tabular}

*information provided by parents in quotations 
While registered in a postsecondary program, she received credits for her work at McDonald's. The mother stated that with her behind-the-scenes advocacy, a supportive environment, and her daughter's sweet disposition, she "thrived" at the restaurant. However, when a former high school teacher "made fun of her for becoming a 'lifer' at McDonald's," she felt so humiliated she quit. That was the beginning of a downward spiral, according to the mother, who reported that her daughter was now living with "three druggy guys" and had fallen into the "drinking and drug crowd." Of the man who was registered in the culinary arts program (\# 13), his mother stated that "he was paranoid and all he could focus on were the cooking knives; he got lost in the class as no one knew about his disabilities. . . . Also, [he] can only handle two directions at a time and when four or five are given, nothing is done." She seemed to recognize the poor fit: "We realized that the food business was not an easy place for someone like our son to survive." Hence, a relationship between secondary disabilities and employment among these adults with FASD who had been registered in postsecondary programs was found.

\section{Time of Diagnosis, Persistence, and Employment}

The four adults who had an early diagnosis (\#2, \#7, \#8, and \#11) were all employed, with two in their chosen field of study. Only two of four adults with FASD who were diagnosed between the ages of seven and 18 years were working (siblings \#5a and \#5b). The two had a secondary disability of substance abuse (\#1 and \#10b). Of the five adults diagnosed between the ages of 19 and 35 years, the two siblings were working (\#6a and \#6b), \#9 was a "gamer," \#10a was "drifting from guy to guy," and \#13 "spends a great deal of time on his computer." Two adults received a diagnosis when they were 36 or older; one of these individuals was working part-time (\#12) and, according to his mother, the other one was doing "nothing [except] drugs." In summary, the data for the adults with FASD suggest that an early diagnosis may be a protective factor against unemployment.

Six of the adults persisted in their postsecondary studies until graduation, and all of these were employed at the time of the study. Two found work in the area in which they had studied (\#7, hairdressing, and \#12, dental technology) and three were from one family ( $\# 5 a$ a, $\# 5 b$, and $\# 5 c$ ). The sixth individual was still in school and employed by an airline. Among the group of adults who persisted, only \#7 had a diagnosis before age three; the early diagnosis may have helped the parent plan realistic goals and find support services for her daughter. The data point to four factors related to success in the postsecondary studies of adults with FASD: a teacher who provided extra time for practice, acquisition of coping skills coupled with maturity, their own hard work and determination, and help from family and friends. It is remarkable that while in college, two of the adults did not request any accommodations from their instructors. One mother (\#12) stated that her daughter did not think she needed any help to pass her courses. Another woman commented that her son (\#11) "wouldn’t ask; there has always been an element of denial." However, with the assistance of her mother, who attended an initial meeting with administrators, adult \#7 did request accommodations. The parent of adults \#5a, \#5b and \#5c also stated that she helped her children advocate by searching for the names of people who could help them. In summary, unlike employment, persistence in postsecondary education among this group of adults with FASD was not linked to an early diagnosis, but rather to the support they could garner (accommodations, both academic and emotional), their own abilities, and hard work. It should also be noted that all of these adults with FASD who persisted and graduated were employed, and it is possible that the work habits, strategies, skills, and abilities that contributed to their success in their postsecondary studies also helped them keep their jobs.

\section{Employment Experiences of Interview Participants}

Four of the adults with FASD agreed to be interviewed and revealed their perspectives on their experiences in the workforce. They were Johnny (\#8), Alan (\#13), Ted (\#9), and Sonja (\#12) (these are pseudonyms, used to protect the identities of the individuals). Johnny had been enrolled in a welding program, but dropped out after the first year. Since then, he had held a few jobs; at the time of the interview, he was employed at Walmart. He had worked there for two years, in the frozen food and dairy sections, stocking shelves, which he said "is not that hard of a job." Johnny seemed to enjoy the work and had made friends with his co-workers. However, over the years, keeping a job had been a challenge for him. His mother recalled a time when her son was working alone on the evening shift at a gas station. He sometimes drank, watched movies his mother described as "inappropriate," and left before his shift was over. Hence, she felt that he needed close supervision to keep him on task.

Alan had been registered in a culinary arts program and had also worked part-time at a grocery store in the food preparation section, where his mother was adamant that he receive support and "not too much pressure." She explained that because her son presents as "articulate and competent," the support ended. She recalled that "he was sent to other areas or asked questions by other staff and he just fell apart." Additionally, the mother perceived that Alan's support worker, who was hired to ensure that he did not become overwhelmed, had overestimated his abilities and therefore did not provide the required level of assistance. Alan stated that he now prefers volunteer work to paid work, because the expectations are lower and "it's more about helping people than trying to earn a pay check.”

Unlike Alan, Ted had no formal training in culinary arts, but had worked in a number of restaurant kitchens. However, like Alan, he had had a "crash," two years earlier. His therapist advised him to "take some time off to try to figure yourself out, to try to rebuild yourself.” Ted had thought about returning to the workforce, but was still experiencing "terrible mood swings" and did not want "to put other people through that, especially an employer." Neither Alan nor Ted was working at the time of the interview. 
Sonja had been employed as a dental technician; she explained that her postsecondary program and her skills as an artist helped her get the job. After three years, she left, because her physical and mental health were "going downhill—quickly." She explained that it was very hard to focus for long periods of time. The employer required specific hours of work, and the only reason she survived for three years was that she was permitted to take a month's leave during the slow summer period. She called this her "decompression time." When the owner announced the end of this practice, Sonja stayed until the next summer, then quit. At the time of the interview, she was employed as a casual postal worker and was selling her art at a local gallery. She made some suggestions for employers with workers who have FASD:

- Offer part-time employment, depending on the abilities of the individual.

- Permit employees to get up and take a break periodically.

- Permit employees to take a day off if they need it.

- Ensure there is some variety in the job.

The comments of the four interview participants indicated that they all had trouble keeping a job over a long period of time. In some cases, problems occurred because there was not a good fit between the individual's skills and abilities and the demands of the position. Other times, it seemed that if the employer had made a few accommodations, the individual would have been able to continue in the job for a longer period of time. The data also showed that for some adults with FASD, employment may be compromised by mental and physical health problems.

\section{Independent Living}

Johnny, 26 years old and the only one of the four with a diagnosis of FAS, was still living at home with his parents. He would have liked to try living on his own, but his mother felt that he needed supervised housing, and Johnny also figured that he would need the income from two jobs to cover the costs of living independently. Alan was in a supportive living home and Ted lived alone in an apartment. Due to their disabilities, they both received financial support from their respective provincial governments. Alan also benefited from extra "staffing hours" from another provincial program, to assist in managing his affairs. Ted's additional support came from money provided by his mother: "She'll give me \$20 here and there.” Like Ted, Sonja lived alone in an apartment. For the first year after leaving her job she received employment insurance benefits, but since then had been living off her savings and the modest income generated from her work as a casual employee at Canada Post and the sale of her art.

\section{Goals for the Future}

Ted and Alan, both diagnosed later in life, were focused on managing their secondary disabilities (mental health problems). Ted spoke of "constantly feeling so tired and so overwhelmed by everything." After a while, he explained, "I kind of gave up and I started sitting at home a lot and I wouldn't do anything.” Although he wanted to work and be more socially active, he had no career goals. Ted's first priority was to be happy and content with himself, and with the help of medications, he hoped to start over and "make a new person out of myself." Alan perceived that he was on the "right medication" and was more focused on personal goals than on having a career. He wanted to make his own decisions without others telling him about his mistakes and failures, and had modified his goals "to fit how [his] life is." Both men participated in society through the Internet and met people through virtual social networking websites. Johnny had decided not to return to the welding program, but had looked into courses that would help him become a personal trainer. However, at the time of the interview, he had not gone beyond investigating this possibility. Sonja would have liked to be able to live off the proceeds of her art, so that she wouldn't have to worry about work and paying her rent. She said she found it hard to focus on both at the same time: "That's another characteristic of FASD; it is hard to juggle all of these things." She is directed towards the goal of supporting herself financially. These three participants were attempting to take control of their lives and to heal themselves. Sonja summed it up as follows: "I've decided that I'm not going to try and fit a triangle into a circle any more. It doesn't work. I have to do what's best for me and not what society expects of me."

\section{Thoughts on FASD}

Johnny had an early diagnosis and had never considered himself to be "normal." He said he sometimes wondered "what it feels like to have a normal brain. To be normal. To be like other people and how they cope." The other three participants were diagnosed as adults, so they were unaware that the other disabilities and failures they had experienced while growing up were related to prenatal alcohol exposure. Until the diagnosis, Ted and Alan did not know about the limitations imposed by FASD. They had life expectations that were similar to their peers, yet FASD had made it impossible to realize these goals. Alan described the limitations as "reaching for a brass ring but never being able to grasp it." Ted used a similar metaphor:

"For the last 30 years I didn't know that a plate glass window was there. And then all of a sudden I reached out my hand, 'Hey, there's something blocking me.' And then it clicks in why things have been going wrong in my life, and why I have felt certain ways, and why I've acted certain ways.”

Ted felt angry about having FASD. He stated, "You're messed up and you've been messed up all your life and it's because of somebody else and their irresponsibility. And it makes you really mad. It goes right to your heart; it breaks your heart." In contrast, Alan appeared to have accepted his diagnosis and the loss of personal dreams. He said, "You start with the best goals and you pull it back until you know you can do it. [FASD] has changed a lot of my life. There are a lot of things I can't do because I have FASD. And I just have to accept it.”

All three of the oldest participants described feeling stigmatized because they have FASD. They talked about how others, such as friends and co-workers, don't perceive them as different at first, but treat them differently once 
they learn about the diagnosis. Alan said that their "whole outlook on me changes," while Ted thought he was perceived as a "brain-damaged freak." Sonja talked about job situations in which she was initially treated like the others, until her co-workers noticed over time that she did not always understand instructions. Sonja felt that once they decided she was "different," they discriminated against her. She believed this was wrong, because her coworkers would never have made unrealistic demands of someone with an obvious physical disability, yet they did not adjust their expectations of a person with brain damage. Sonja proposed that "normals should be taught how not to discriminate against us."

\section{Discussion}

The purpose of this exploratory study was to examine the employment experiences of adults with FASD who had attended postsecondary programs. Data were provided by 13 women, representing 17 adult children with FASD, who responded to forced-choice and open-ended questions in an electronic survey. Four of the adult children (all of whom were adopted) also participated in in-depth interviews. Unlike the results reported by other researchers (Salmon \& Beutow, 2012; Spohr et al., 2007; Streissguth et al., 1996), in this study more than half of the adults with FASD were employed. This finding was more consistent with the results of Salmon's 2008 study, in which she reported that four of nine adults with FASD had jobs. However, we found that most of the jobs were in the service sector, and many of the adults were working on a part-time basis. Moreover, when the study was conducted, only three of the adults were working in the field in which they studied (hairdressing, computer technology, and dance).

In other studies, early diagnosis was shown to be a protective factor for individuals with FASD (Streissguth et al., 2004). In this study, four of the 17 adults had been diagnosed before age three, and all of these were employed, with two of them working in the area of their postsecondary studies. Hence, a positive relationship between early diagnosis and employment was found in the current research. It is possible that an early diagnosis gave the parents an opportunity to make realistic career and education plans for their sons or daughters. It is also likely that these parents knew early on that their children would need their support in order to succeed, and were able to provide it. The study also found that the six adults who persisted in their postsecondary studies until graduation were all employed at the time of the research. Kerns and colleagues (1997) reported that problems with memory, attention, and processing continue past adolescence; the adults with FASD who persisted may have had fewer deficits in these areas than those who did not. Additionally, their relatives did not indicate that they had secondary disabilities that interfered with their functioning. Although Streissguth and O'Malley (2000) concluded that a high proportion of adults with FASD are unable to work independently, this outcome is inconsistent with our findings on adults who had been in a postsecondary program. It is possible that the personal support systems, work habits, strategies, skills, and abilities that helped them persist in their studies may also have helped them maintain their employment. In contrast, in this study, adults with FASD who did not graduate from college or were not employed were described by their relatives as having mental health problems (e.g., depression, substance abuse), the symptoms of which may have contributed to these negative outcomes.

The interview data provided additional insight into the employment situations of adults with FASD. There were limits to the educational and vocational achievements of the interview subjects that were linked to their disabilities. Three of the four had not completed their postsecondary studies, for reasons that included mental health problems and attention deficits. While one of them was able to hold a full-time job for three years in her field of postsecondary study, she ultimately had to leave it because of mental and physical exhaustion. At the time of her interview, she was working occasionally for Canada Post. The two older men were focused on managing their depression and mood swings and were participating in society in a limited way (mostly virtually). Only the 26-year-old male who had received a diagnosis before age three had regular shifts, in a department store. These stories, along with the survey data, demonstrated that although some adults with FASD may be able to complete postsecondary programs, they are not all able to hold full-time jobs in the area of their studies. For the most part, if individuals were employed, it was on a part-time basis.

The interview and survey data also highlighted some of the problems encountered by adults with FASD in the workplace. For example, Alan presented superficial characteristics that appeared to suggest he was capable of completing tasks without assistance. Hence, his support worker overestimated his abilities and did not provide the required support, and Alan was eventually let go from his job at the grocery store. Sonja spoke of being marginalized by co-workers when they discovered that she had trouble remembering things. Additionally, the mother of the woman who became a hairdresser wrote about how her daughter initially had difficulty keeping a job because she could not follow procedures. Therefore, while some adults with FASD were able to find employment, keeping jobs for long periods of time was challenging.

\section{Protective Factors}

Early diagnosis and a stable family life between the ages of eight and 12 years were identified by Streissguth and her colleagues (2004) as protective factors for individuals with FASD. The results of this research support that finding, and based on our findings we believe there is a positive association between early diagnosis and the possibility of being employed as an adult. While the family situations during childhood of the adults who were registered in postsecondary programs are not known, 11 of the 13 respondents to the survey were mothers who were able to answer questions about their son's or daughter's elementary school experience. Their responses suggested that they had been living with, or had contact with, their children with FASD for a long period of time and that there 
was some stability in the homes. The findings of this study extend our knowledge, as we found that having a support network in adulthood was an asset for these individuals with FASD. While they were in college, their parents advocated for them, helped them advocate for themselves, and assisted with their assignments. The parents also helped manage the individuals' financial affairs, permitted them to live at home, and provided financial assistance and moral support. Friends and teachers also helped some of these adults complete their assignments and develop skills. Hence, the asset of a support network consisting of parents, friends, and teachers contributed to the success of adults with FASD in postsecondary education and on the job.

The results of this research support the call for early identification of FASD and for physicians and mental health professionals to become better informed about this disability. Other authors have noted that adults with FASD often have difficulties obtaining a diagnosis (Chudley et al., 2007; Salmon, 2008; Salmon \& Buetow, 2012) and that FASD is usually discovered while the patient is undergoing assessment or treatment for another problem (Clark, Minnes, Lutke, \& Ouellette-Kuntz, 2008). More than 60\% of the patients with FASD involved in a longitudinal study conducted in Germany had a psychiatric disorder that persisted over time (Spohr et al., 2007). An even higher proportion of the adults studied by Streissguth and O’Malley (2000) had clinical depression during adulthood (94\%). Previous research shows that individuals with FASD frequently develop mental health problems as another disability, which was consistent with the findings of this study. The implication is that mental health professionals should ensure that they are informed about FASD and its symptoms among adolescents and adults.

Streissguth and O'Malley (2000) contend that individuals with FASD usually do not qualify for social services on the basis of intellectual disability because they have an IQ score higher than 70, even though their adaptive functioning is often far below their IQ level. However, some of the individuals in this research were able to access community support services, and one of them encountered problems with supported employment because his superficial characteristics gave the appearance of normal functioning. Hence, training for social services workers on the characteristics of people with FASD, and particularly the difficulties they may have with memory, attention, and processing, is also warranted.

Ryan, Bonnett, and Gass (2006) pointed out that adults with FASD who do receive services are frequently "lost" in the system and need someone to advocate for them. Citizen Advocate organizations were founded in the 1970s to provide friendship and assistance in everyday living to individuals with developmental disabilities (Hildebrand, 2004). Citizen advocacy organizations may also be a source of help for adults with FASD who are living on their own and would benefit from occasional help with advocacy, the opportunity to discuss a problem at school or work, and friendship with someone who has similar interests. Citizen Advocates could therefore assist marginalized adults with FASD to become more active participants in society.

\section{Limitations}

A key strength of this study is the descriptive information it provided. It represents one of the first studies to provide data on adults with FASD who had been registered in a postsecondary program. A limitation of this research is the small number of respondents to the survey. Although the link was sent to many e-mail lists in North America, only 17 women participated. This low number may be because (1) for various reasons, only a few adults with FASD attend postsecondary programs, (2) there was only a small proportion of eligible families who were on those particular electronic mailing lists, (3) response bias was a factor (i.e., families with adult children with FASD who had positive educational and employment outcomes were more likely to participate than families with poor outcomes), and (4) electronic mailing list requests generally yield low response rates.

\section{Future Research}

The comments of Johnny, Ted, Alan, and Sonja help us to understand the negative and lifelong effects of FASD from their perspectives. FASD is a hidden disability and, as one mother noted, "there are a lot of people like my son who are fairly high functioning and. . . . are easily misunderstood as being normal.” But as the four adults who were interviewed noted, they do not feel normal; for three of them, finding out they were unable to achieve the same adult outcomes as their peers was difficult to accept. The effects of FASD on the individual, the family, and the community need to become better known by educators, the medical community, social service workers, and the general public. Future research should therefore involve long-term studies on individuals with FASD and their families, so that the pervasive effects of FASD are more fully understood. Studies should also be conducted on the community services that may be provided to adults with this disability, to learn more about how support networks assist individuals with FASD as they make their way through life.

\section{References}

Brantlinger, E., Jimenez, R., Klingner, J., Pugach, M., \& Richardson, V. (2005). Qualitative studies in special education. Exceptional Children, 71, 195-207. doi:10.1352/0047-6765(2005)43<92:IOEAWA>2.0. $\mathrm{CO} ; 2$

Charmaz, K. (2000). Grounded theory objectivist and constructivist methods. In N. K. Denzin \& Y. S. Lincoln (Eds.), Handbook of qualitative research (2nd ed.) (pp. 509-536). Thousand Oaks, CA, United States: Sage Publications.

Chudley, A., Conry, J., Cook, J., Loock, C., Rosales, T., \& LeBlanc, N. (2005). Fetal alcohol spectrum disorder: Canadian guidelines for diagnosis. Canadian Medical Association Journal, 172, S1-S15. doi:10.1503/cmaj. 1040302 
Chudley, A., Kilgour, A., Cranston, M., \& Edwards, M. (2007). Challenges of diagnosis in fetal alcohol syndrome and fetal alcohol spectrum disorder in the adult. American Journal of Medical Genetics, Part C, Seminars in Medical Genetics, 145, 261-272. doi: 10.1002/ajmg.c.30140

Clark, E., Lutke, J., Minnes, P., \& Ouellette-Kuntz, H. (2004). Secondary disabilities among adults with Fetal Alcohol Spectrum Disorder in British Columbia. Journal of FAS International, 2, 1-12.

Clark, E., Minnes, P., Lutke, J., \& Ouellette-Kuntz, H. (2008). Caregiver perceptions of the community integration of adults with Fetal Alcohol Spectrum Disorder in British Columbia. Journal of Applied Research in Intellectual Disabilities, 21, 446-456. doi: 10.1111/j.1468-3148.2007.00414.x

Creswell, J. (2007). Qualitative inquiry and research design: Choosing among five traditions (2nd ed.). Thousand Oaks, CA, United States: Sage Publications.

Duquette, C., \& Stodel, E. (2005). School experiences of students with fetal alcohol spectrum disorder. Exceptionality Education Canada, 15, 51-76.

Duquette, C., Stodel, E., Fullarton, S., \& Hagglund, K. (2006). Persistence in high school: Experiences of adolescents and young adults with fetal alcohol spectrum disorder. Journal of Intellectual and Developmental Disability, 31, 219-231. doi:10.1080/ 13668250601031930

Freeman, M., de Marrais, K., Preissle, J., Roulston, K., \& St. Pierre, E. (2007). Standards of evidence in qualitative research: An incitement to discourse. Educational Researcher, 36, 25-32. doi:10.3102/ 0013189X06298009

Hildebrand, A. J. (2004). One person at a time: Citizen advocacy for people with disabilities. Northampton, MA, United States: Brookline Books.

Kerns, K. A., Don, A., Mateer, C. A., \& Streissguth, A. P. (1997). Cognitive deficits in non-retarded adults with fetal alcohol syndrome. Journal of Learning Disabilities, 30, 685-693. doi:10.1177/ 002221949703000612

Marshall, C., \& Rossman, G. (2006). Designing qualitative research (4th ed.). Thousand Oaks, CA, United States: Sage Publications.

Mertens, D. (2005). Research and evaluation in education and psychology (2nd ed.). Thousand Oaks, CA, United States: Sage Publications.

Miles, M., \& Huberman, M. (1994). Qualitative data analysis: A sourcebook of new methods (2nd ed.). Newbury Park, CA, United States: Sage Publications.

Ryan, D., Bonnett, D., \& Gass, C. (2006). Sobering thoughts: Town Hall meetings on fetal alcohol spectrum disorders. American Journal of Public Health, 96, 2098-2101. doi:10.2105/AJPH.2005. 062729

Salmon, J. V. (2008). Fetal alcohol spectrum disorder: New Zealand birth mothers' experiences. Canadian Journal of Clinical Pharmacology, 15(12), e191e213.

Salmon, J. V. \& Buetow, S. A. (2012). An exploration of the experiences and perspectives of New Zealanders with fetal alcohol spectrum disorder. Journal of
Population Therapeutics and Clinical Pharmacology, 19, e41-e50.

Spohr, H., Willms, J., \& Steinhausen, H. C. (2007). Fetal alcohol spectrum disorders in young adulthood. Journal of Pediatrics, 150, 175-179. doi:10.1016/ j.jpeds.2006.11.044

Strauss, A., \& Corbin, J. (1998). Basics of qualitative research: Techniques and procedures for developing grounded theory. Newbury Park, CA, United States: Sage Publications.

Streissguth, A. P., Barr, H., Kogan, J., \& Bookstein, F. (1996). Understanding the occurrence of secondary disabilities in clients with fetal alcohol syndrome (FAS) and fetal alcohol effects (FAE): Final report to the Centers for Disease Control and Prevention on Grant No. R04/CCR008515 (Tech. Report No. 96-06). Seattle, WA, United States: University of Washington, Fetal Alcohol and Drug Unit.

Streissguth, A. P., Bookstein, F., Barr, H., Sampson, P., O’Malley, K., \& Young, J. K. (2004). Risk factors for adverse life outcomes in fetal alcohol syndrome and fetal alcohol effects. Journal of Developmental \& Behavioural Pediatrics, 25, 225-228. doi:10.1097/ 00004703-200408000-00002

Streissguth, A. P., \& O’Malley, K. (2000). Neuropsychiatric implications and long-term consequences of fetal alcohol spectrum disorders. Seminars in Clinical Neuropsychiatry, 5, 177-190. doi:10.1053/ scnp.2000.6729 